\title{
Evaluation of the Prevalence, Progression and Severity of Common Adverse Reactions (Lipodystrophy, CNS, Peripheral Neuropathy, and Hypersensitivity Reactions) Associated with Anti-Retroviral Therapy (ART) and Anti-Tuberculosis Treatment in Outpatients in Zimbabwe
}

Tafireyi Nemaura ${ }^{1,2}$, Milcah Dhoro ${ }^{1}$, Charles Nhachi ${ }^{2}$, Gerard Kadzirange ${ }^{2}$, Prosper Chonzi ${ }^{3}$ and Collen Masimirembwa ${ }^{1 *}$

${ }^{1}$ African Institute of Biomedical Science \& Technology, P.O. Box 2294, Harare, Zimbabwe

${ }^{2}$ Faculty of Medicine, College of Health Sciences, University of Zimbabwe, Zimbabwe

${ }^{3}$ Department of Health, Harare City Council, Zimbabwe

\begin{abstract}
Introduction: The use of many anti-retroviral drugs has been associated with a myriad of adverse drug reactions (ADRs) which could limit successful treatment outcome with respect to patient compliance and quality of life. An additional consideration is the high incidence of HIV infection with tuberculosis (TB) in Southern Africa, including Zimbabwe, and the use of co-treatment regimens.

Methods: The study is a cross sectional, case-control study of 433 out-patients conducted at two hospitals in Zimbabwe. The patients were profiled for adverse reactions namely central nervous system side-effects (CNS), lipodystrophy (LD), skin hypersensitivity (SH), and peripheral neuropathy (PN). Assignment of the case and the control status of a patient was done based on occurrence of these adverse drug reactions in each of the HIVIAIDS only, TB only and HIV/TB co-infection patient groups.

Results: Among the HIVIAIDS only treatment group $(n=240)$, the incidences of major ADRs were PN $(63 \%)$, LD $(38 \%)$, CNS $(29 \%)$ and SH $(21 \%)$. In the TB only treatment group ( $n=92)$, the major ADRs were PN $(49 \%)$, CNS (29\%), and SH (14\%). In the HIV-TB co-treatment group ( $n=98)$, the major ADRs were PN (64\%), CNS (39\%), LD $(6 \%)$ and $\mathrm{SH}(18 \%)$. A significant number of females were on alternate first line treatment that has no stavudine as compared to males $(\mathrm{OR}=1.98, \mathrm{Cl}(1.1,3.59) ; \mathrm{p}=0.03)$. Occurrence of $\mathrm{CNS}$ adverse drug reactions were more associated with patients on efavirenz than other HIV-drug combinations ( $43 \%$ vs. $17 \%$, $p<0.00001)$.

Conclusion: The use of anti-retroviral drugs and anti-TB drugs is associated with very high incidences of adverse drug reactions. There is therefore need to understand the pharmacokinetic and pharmacodynamic mechanisms of these ADRs so as to identify patients at risk and to provide guidelines for the choice of drug and dosage to ensure safe and efficacious treatment outcomes.
\end{abstract}

\section{Introduction}

Sub-Saharan Africa carries the heaviest burden of the HIV and AIDS pandemic. Zimbabwe is within the epicentre of this pandemic with an HIV infection prevalence of $14.3 \%$ in the $\geq 15$ years age group [1] . The prevalence of Tuberculosis (TB), the major opportunistic infection causing death in HIV and AIDS patients is also high with $60-80 \%$ of TB patients being estimated to be HIV positive [1-3]. SubSaharan African populations were late in receiving anti-retroviral therapy (ART) resulting in high mortality rates among HIV and AIDS patients. Over the years, since 1985, HIV and AIDS overtook malaria as the leading cause of death in Africa [4].

High mortality rates due to HIV and AIDS declined in resource rich countries with the discovery and access to anti-retroviral drugs (ARVs), starting with zidovudine in 1985 [5]. Through the Global Fund and concerted efforts of nongovernmental organisations, access to ARVs steadily increased in Sub-Saharan Africa. In addition, the Zimbabwean government initiated the AIDS Levy for all workers in 1999 as a national response to the HIV/AIDS pandemic. The AIDS Levy is a percentage of taxable income (3\%) taken from every Zimbabwean employee's salary per month and deposited into the National AIDS Council (NAC) account for use in programs to combat HIV/AIDS in Zimbabwe [6]. By 2008, over 1 million people were infected with HIV and 500000 required ART, but only a modest 100000 currently have access to these life-saving drugs [7]. Given the recent evidence that ART not only reduces mortality rates but also reduces transmission rates [8], ART holds the promise to halting the spiral spread of the HIV pandemic.

The access to ARVs has not been without difficulties. Earlier use of monotherapy was associated with the emergence of drug resistant variants of HIV [9]. Research in the 1990s led to the discovery of the more effective highly active anti-retroviral therapy (HAART) $[10,11]$. The use of ARVs was and continues to be associated with moderate, severe and sometimes life threatening adverse drug reactions. For many patients there is a shift from limited access to ARVs to issues of safety and efficacy in their use. As the use of ARVs was accessed by many patients across the world and used for long

*Corresponding author: Collen Masimirembwa, Department of DMPK \& Bioanalytical Chemistry, African Institute of Biomedical Science \& Technology, Dominion House, 211 Herbert Chitepo and Sam Nujoma Street Harare, Zimbabwe, Tel: 2634 710563; E-mail: collenmasimirembwa@yahoo.com

Received February 26, 2013; Accepted April 10, 2013; Published April 17, 2013

Citation: Nemaura T, Dhoro M, Nhachi C, Kadzirange G, Chonzi P (2013) Evaluation of the Prevalence, Progression and Severity of Common Adverse Reactions (Lipodystrophy, CNS, Peripheral Neuropathy, and Hypersensitivity Reactions) Associated with Anti-Retroviral Therapy (ART) and Anti-Tuberculosis Treatment in Outpatients in Zimbabwe. J AIDS Clin Res 4: 203. doi:10.4172/2155-6113.1000203

Copyright: (c) 2013 Nemaura T, et al. This is an open-access article distributed under the terms of the Creative Commons Attribution License, which permits unrestricted use, distribution, and reproduction in any medium, provided the original author and source are credited. 
Citation: Nemaura T, Dhoro M, Nhachi C, Kadzirange G, Chonzi P (2013) Evaluation of the Prevalence, Progression and Severity of Common Adverse Reactions (Lipodystrophy, CNS, Peripheral Neuropathy, and Hypersensitivity Reactions) Associated with Anti-Retroviral Therapy (ART) and Anti-Tuberculosis Treatment in Outpatients in Zimbabwe. J AIDS Clin Res 4: 203. doi:10.4172/2155-6113.1000203

periods, many side effects became apparent for some of the drugs [12].

In Zimbabwe, the $1^{\text {st }}$ line therapy is composed of two nucleoside analogue inhibitors (chosen from stavudine, or zidovudine and lamivudine) and a non-nucleoside analogue inhibitor, Nevirapine or Efavirenz [6]. Zimbabwe is now phasing out stavudine in favour of tenofovir/ zidovudine as of April 2011 as per WHO treatment guidelines [13]. A number of studies are now appearing on safety in the use of ARVs in HIV/AIDS patients in Zimbabwe and other Sub Saharan African countries [14,15]. Such studies are important at patient level, so that patients are given drugs and doses that are safe and efficacious, and at national ARV procurement policy level, so that government procures the right drugs.

In this study, we have evaluated the prevalence, progression and severity of adverse effects to commonly used ARVs and anti-TB drugs in Zimbabwe. Subjects for the study were HIV/AIDS, TB and HIVTB outpatients who had been on different treatment regimens and for different periods.

\section{Materials and Methods}

Study Population: A cross sectional, case-control, study of HIV/ AIDS and/or TB-infected patients who attended the Chitungwiza and Wilkins Hospitals in Harare, Zimbabwe was conducted. Approval to conduct the studies was obtained from the Medical Research Council of Zimbabwe (MRCZ) and the respective Hospital Authorities. Patients participated voluntarily after signing the consent form. A total patient population of 433 was examined. HIV infected and HIV-TB coinfected patients paid two visits to the hospital. On the first day consent was obtained and blood samples collected for drug concentration and genotyping analyses. On the second day, the questionnaire was administered and another blood sample was collected. Patients with TB only and on anti-TB drugs paid one visit to the hospital for purposes of giving consent, responding to the questionnaire and blood collection. The inclusion criterion was that patients had to be adults ( $\geq 18$ yrs of age) and HIV/AIDS and/or TB-infected. Patients too frail to undertake the required two visits and relatively long waiting times and examination procedures were excluded. The patients had to be on HIV/AIDS and/or TB treatment. Patients participated in the evaluation and physical examination for lipodystrophy, skin hypersensitivity, peripheral neuropathy and CNS side effects. Severity of adverse drug reactions were identified from grade 1 to 4 according to WHO guidelines (I-Mild, II-Moderate, III-Severe, and IV-Life Threatening, Table 1) $[16,17]$. Each patient provided information for a questionnaire which captured patient demographic information, medical history, and specific questions related to the 4 ADRs which are subject of evaluation in this study. For each of the 4 adverse drug reactions evaluated, CNS, $\mathrm{SH}, \mathrm{LD}$ and $\mathrm{PN}$, the controls were those patients who showed no signs of a side effect both by self evaluation and the nurse's evaluation. For each of the 4 adverse drug reactions, cases were the ones who showed signs of a side effect both by self evaluation and the nurse's evaluation.

Statistical Analysis: Statistical analysis was done using R, and STATA. Means and medians (interquartile range) were used to describe parametric data and non-parametric data, respectively. Categorical data was compared using $\chi^{2}$ test (or Fisher's exact test), and continuous data were compared using student's T-test or Mann-Whitney test, and Kruskal Wallis whichever was appropriate.

\section{Results}

\section{Overview of ADRs}

The enrolment attracted 433 patients but three were lost to follow up on the second day. A total of 430 patients (35\% were males and $65 \%$ female) were therefore subsequently evaluated for ADRs. There were 240 patients on ART alone, 92 patients on TB treatment only, and 98 patients on both ART and anti-TB treatment. Of those on ART alone $69 \%$ were on a stavudine containing regimen and $31 \%$ on other combinations including tenofovir and zidovudine. Most of the ART group (59\%) were on nevirapine as the NNRTI and $40 \%$ on efavirenz. Of those on both ART and TB treatment, $92 \%$ were on a stavudine containing treatment and $8 \%$ on other combinations including tenofovir and zidovudine. All on the HIV/TB co-treatment were on efavirenz as the NNRTI component of their treatment. All TB treatment regimens had isoniazid and rifampcin as part of the combination therapy.

Of the patients $(n=55)$ on a zidovudine containing regimen, $40 \%$ had been transferred from stavudine treatment because of lipodystrophy and $27 \%$ because of peripheral neuropathy, with $11 \%$ due to both side effects. The frequencies of females who were on zidovudine containing regimens and on tenofovir containing regimens were $80 \%$ and $79 \%$ respectively. Considering patients who were on tenofovir containing regimen $(n=29), 38 \%$ had been transferred from a stavudine containing regimen due to lipodystrophy and $31 \%$ due to peripheral neuropathy. A significant number of females $(\mathrm{OR}=1.98$, CI $(1.1,3.59) ; \mathrm{p}=0.03)$ compared to males were on the first line HIV/AIDS treatment that is the alternative to the stavudine containing treatment. The alternative first line treatment consisted of either tenofovir or zidovudine as substitutes of stavudine due to either peripheral neuropathy or lipodystrophy.

In this study we observed that $83 \%$ of the 430 patients on HIV/ AIDS, HIV $+\mathrm{TB}$ and $\mathrm{TB}$ treatment exhibit at least one of the four adverse drug reactions (ADRs) evaluated, i.e. lipodystrophy, peripheral neuropathy, skin hypersensitivity reactions and central nervous systems

\begin{tabular}{|c|c|c|c|c|c|}
\hline $\begin{array}{l}\text { Adverse Drug Reactions (ADRs) and } \\
\text { their characteristics }\end{array}$ & Grade 0 & Grade I-Mild & Grade II- Moderate & Grade III- Severe & Grade IV-Life Threatening \\
\hline $\begin{array}{l}\text { Lipodystrophy: } \\
\text { Fat gain/loss on different parts of body e.g. } \\
\text { cheeks, lips, unusual fat redistribution. } \\
\text { Skin Hypersensitivity: } \\
\text { Skin rashes, Skin colour changes, Itchiness. } \\
\text { CNS ADRs: } \\
\text { Hallucinations, Headaches, Insomnia. } \\
\text { Peripheral Neuropathy: } \\
\text { Numbness, tinginess, pain at ends e.g. } \\
\text { fingers. }\end{array}$ & $\begin{array}{l}\text { No reporting of } \\
\text { ADR's }\end{array}$ & $\begin{array}{l}\text { Symptoms causing no } \\
\text { or minimal interference } \\
\text { with usual social \& } \\
\text { functional activities. }\end{array}$ & $\begin{array}{l}\text { Symptoms causing } \\
\text { greater than minimal } \\
\text { interference } \\
\text { social } \quad \& \quad \text { usual } \\
\text { activities. }\end{array}$ & $\begin{array}{l}\text { Symptoms causing } \\
\text { inability to perform usual } \\
\text { social and functional } \\
\text { activities. }\end{array}$ & $\begin{array}{l}\text { Symptoms causing } \\
\text { inability to perform basic } \\
\text { self-care functions OR } \\
\text { Medical or operative intervention } \\
\text { indicated to prevent permanent } \\
\text { impairment, persistent disability } \\
\text { or death. }\end{array}$ \\
\hline
\end{tabular}

Table 1: Summarised characteristics and classification of ADRs in patients on ARV's and/or TB drugs. 
Citation: Nemaura T, Dhoro M, Nhachi C, Kadzirange G, Chonzi P (2013) Evaluation of the Prevalence, Progression and Severity of Common Adverse Reactions (Lipodystrophy, CNS, Peripheral Neuropathy, and Hypersensitivity Reactions) Associated with Anti-Retroviral Therapy (ART) and Anti-Tuberculosis Treatment in Outpatients in Zimbabwe. J AIDS Clin Res 4: 203. doi:10.4172/2155-6113.1000203

Page 3 of 7

effects. Table 2 shows the percentage frequency of patients reporting the number of ADRs they were expriencing.

Table 3 shows summary statistics of ADRs evaluated in this study. For the HIV/AIDS only treatment group, the major ADRs were peripheral neuropathy (63\%), lipodystrophy (38\%), CNS side effects (29\%) and skin hypersensitivity (21\%).The most common side effect

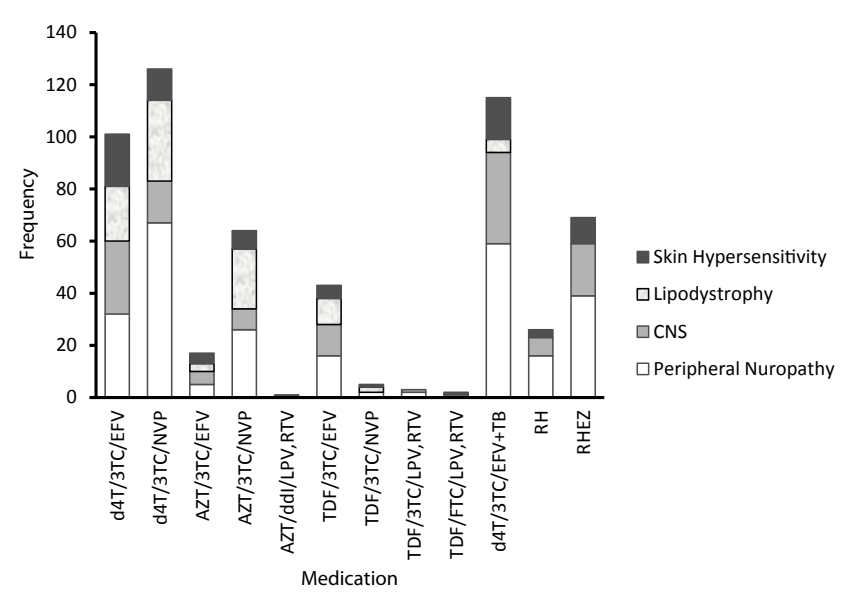

Figure 1: Frequencies of four major ADRs in patients on various HAART (current) regimens. Tenofovir - TDF, zidovudine - AZT, lamivudine - 3TC, stavudine - d4T, nevirapine -NVP, efavirenz - EFV, LPV - lopinavir , retinavir - RTV, rifampcin, isoniazid - $\mathrm{RH}$, rifampicin, isoniazid, ethambutol and pyrazinamide (RHEZ). for those on ART and TB treatment was peripheral neuropathy for $64 \%$ of patients, followed by CNS side effects (39\%), lipodystrophy (6\%) and skin hypersensitivity (18\%). For the patients on TB treatment only, $60 \%$ had a degree of peripheral neuropathy with the majority $(62 \%)$ reporting this at grade I level. The prevalence of other side effects for the TB treatment group was $14 \%$ for skin hypersensitivity and $29 \%$ for CNS side effects. Taking into consideration individuals on ART, only $13 \%$ reported absence of any of the four side effects evaluated in this study. This group were of a relatively lower median age (36yrs vs. $40 \mathrm{yrs}$, $\mathrm{p}=0.07$ ) compared to the group that had at least one side effect. Odds of females to males having at least one of the side effects due to ART treatment were slightly higher $(\mathrm{OR}=1.85(0.91,3.69)$ : $\mathrm{p}=0.059)$. Those who had developed at least one of the evaluated side effects were on a relatively longer mean time on medication (15months vs. 21 months: $\mathrm{p}=0.062$ ). The above results for differences in age, gender and time on medication, however, show no statistical significance at $5 \%$ level for the characteristics investigated.

Figure 1 presents the ADRs data to demonstrate the frequency of each ADR under each of the treatment regiments of the 430 patients. The frequencies of ADRs for $\mathrm{d} 4 \mathrm{~T} / 3 \mathrm{TC} / \mathrm{NVP}$ were in the following decreasing order $\mathrm{PN}>\mathrm{LD}>\mathrm{CNS}>\mathrm{SH}$ and for those on $\mathrm{d} 4 / 3 \mathrm{TC} / \mathrm{EFV}+\mathrm{TB}$ (RHEZ/RH) the frequencies were $\mathrm{PN}>\mathrm{CNS}>\mathrm{SH}>\mathrm{LD}$. For patients on $\mathrm{TB}$ treatment alone the frequencies of $\mathrm{ADRs}$ were in the following decreasing order $\mathrm{PN}>\mathrm{CNS}>\mathrm{SH}$.

\section{Lipodystrophy}

Figures 2 and 3 represent a detailed analysis of lipodystrophy

\begin{tabular}{|l|c|c|c|c|}
\hline \multirow{2}{*}{} & \multicolumn{3}{|c|}{ Reported ADRs' } \\
\cline { 2 - 4 } & $\mathbf{1}$ & $\mathbf{2}$ & $\mathbf{3}$ \\
\hline HIVIAIDS treatment (\%) & 42 & 30 & 14 \\
\hline HIVIAIDS-TB treatment (\%) & 45 & 31 & $\mathbf{4}$ \\
\hline TB treatment (\%) & 47 & 20 & 0 \\
\hline
\end{tabular}

Table 2: Percentage frequency for patients reporting the profiled adverse drug reactions that is CNS, PN, LD and SH.

\begin{tabular}{|c|c|c|c|c|c|c|c|c|c|}
\hline \multirow{2}{*}{ Treatment } & & \multicolumn{2}{|l|}{ PN } & \multicolumn{2}{|l|}{ CNS } & \multicolumn{2}{|l|}{ LD } & \multicolumn{2}{|l|}{ SH } \\
\hline & & Case & Control & Case & Control & Case & Control & Case & Control \\
\hline \multirow{6}{*}{ ART } & Females; Males & $116 ; 35$ & $63 ; 26$ & $54 ; 16$ & $125 ; 45$ & $79 ; 11$ & $100 ; 50$ & $39 ; 12$ & $140 ; 49$ \\
\hline & Age (yrs) & $40(35,47)$ & $39(33,46)$ & $40(34,47)$ & $40(34,46)$ & $40(36,46)$ & $40(33,47)$ & $39(34,44)$ & $40(34,47)$ \\
\hline & $\begin{array}{l}\text { Time on Treatment } \\
\text { (months) }\end{array}$ & $17(11,36)$ & $15(9,30)$ & $15(9,24)$ & $17(10,36)$ & $27(15,48)$ & $14(9,23)$ & $18(10,32)$ & $16(10,36)$ \\
\hline & Weight (kg) & $60(52,66)$ & $61(55,67)$ & $61(52,66)$ & $60(54,67)$ & $60(53,68)$ & $60(52,66)$ & $61(54,66)$ & $60(53,67)$ \\
\hline & Height (m) & $1.63(1.59,1.68)$ & 1.64(1.6,1.69) & $1.63(1.6,1.7)$ & $1.63(1.6,1.68)$ & $1.63(1.57,1.66)$ & $1.64(1.6,1.69)$ & 1.63(1.6,1.68) & 1.63(1.6,1.69) \\
\hline & BMI $\left(\mathbf{k g} / \mathrm{m}^{2}\right)$ & $22(20,25)$ & $22(21,24)$ & $22(20,25)$ & $22(20,24)$ & $23(20,25)$ & $22(20,24)$ & $22(20,24)$ & $22(20,25)$ \\
\hline \multirow{6}{*}{ ART-TB treatment } & Females; Males & $35 ; 28$ & $22 ; 13$ & $23 ; 15$ & $34 ; 26$ & $5 ; 1$ & $52 ; 40$ & $10 ; 8$ & $47 ; 33$ \\
\hline & Age (yrs) & $39(34,47)$ & $35(29,39)$ & $37(31,43)$ & $38(33,44)$ & $43(35,49)$ & $38(32,43)$ & $38(32,42)$ & $38(32,43)$ \\
\hline & $\begin{array}{l}\text { Time on Treatment } \\
\text { (months) }\end{array}$ & $6(4,12)$ & $4(3,16)$ & $4.5(3,12)$ & $7(4,13)$ & $27(12,48)$ & $6(4,9)$ & $6(3,8)$ & $6(4,14)$ \\
\hline & Weight (kg) & $58(50,68)$ & $55(47,62)$ & $57(53,65)$ & $56(47,65)$ & $62(55,76)$ & $56(47,65)$ & $63(55,72)$ & $55(47,64)$ \\
\hline & Height (m) & 1.65(1.6,1.72) & $1.62(1.57,1.68)$ & $1.65(1.56,1.7)$ & 1.64(1.6,1.69) & $1.6(1.57,1.66)$ & 1.64(1.6,1.7) & $1.66(1.63,1.74)$ & $1.64(1.58,1.7)$ \\
\hline & BMI $\left(\mathbf{k g} / \mathbf{m}^{2}\right)$ & $21(19,24)$ & $20(19,23)$ & $21(19,25)$ & $21(19,23)$ & $24(22,29)$ & $21(19,23)$ & $23(19,26)$ & $21(19,23)$ \\
\hline \multirow{6}{*}{ TB treatment } & Females; Males & $26 ; 29$ & $17 ; 20$ & $16 ; 11$ & $27 ; 38$ & & $43 ; 49$ & $10 ; 3$ & $33 ; 46$ \\
\hline & Age (yrs) & $39(33,50)$ & $35(30,42)$ & $36(30,45)$ & $37(31,49)$ & & $37(31,45)$ & $38(33,52)$ & $37(31,45)$ \\
\hline & $\begin{array}{l}\text { Time on Treatment } \\
\text { (months) }\end{array}$ & $3(2,7)$ & $4(2,6)$ & $3(2,7)$ & $4(2,7)$ & & $4(2,7)$ & $3(2,6)$ & $4(2,7)$ \\
\hline & Weight (kg) & $62(55,69)$ & $59(52,64)$ & $60(53,70)$ & $60(54,66)$ & & $60(54,66)$ & $63(60,65)$ & $59(53,66)$ \\
\hline & Height (m) & $1.67(1.61,1.72)$ & $1.68(1.62,1.72)$ & $1.62(1.58,1.69)$ & $1.69(1.64,1.72)$ & & $1.68(1.62,1.72)$ & $1.63(1.58,1.7)$ & $1.68(1.62,1.72)$ \\
\hline & BMI $\left(\mathbf{k g} / \mathbf{m}^{2}\right)$ & $22(20,25)$ & $21(19,24)$ & $22(20,27)$ & $21(19,24)$ & & $22(20,24)$ & $23(21,25)$ & $21(19,24)$ \\
\hline
\end{tabular}

Table 3: Summary statistics of adverse drug reactions showing frequencies, median and interquartile range for the independent variables investigated. 


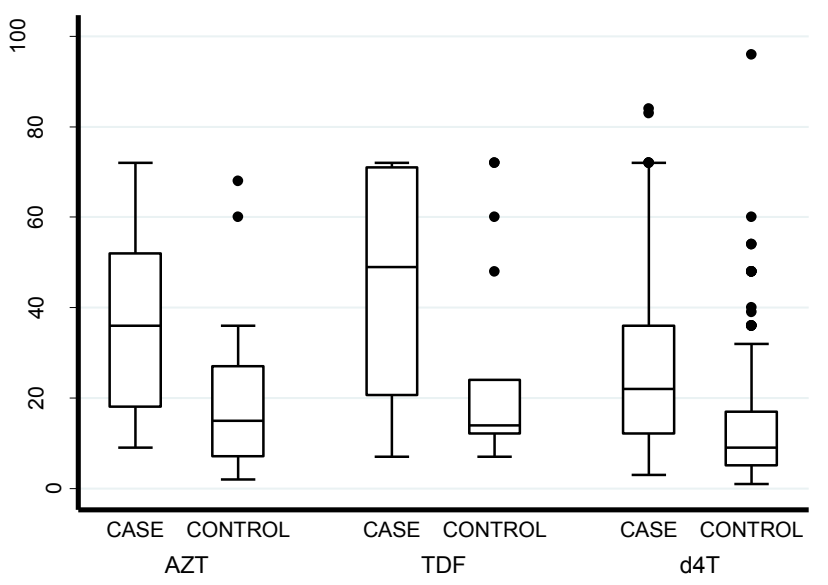

Figure 2: Duration on treatment (months) for the cases and controls for lipodystrophy. Most individuals on AZT containing ART and TDF containing ART (non d4T containing regimens) are on alternative first line treatment having been transferred from d4T because of side effects.

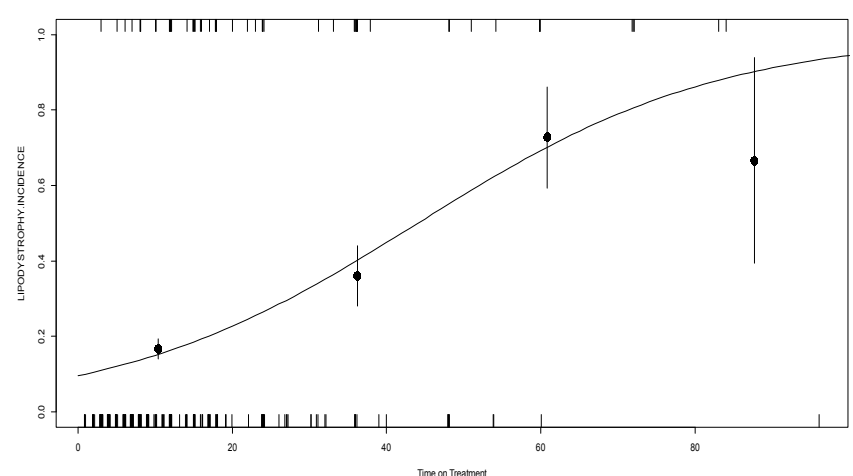

Figure 3: Time (months) on treatment with a stavudine based regimen versus susceptibility to lipodystrophy. The dots are proportions of susceptibility to lipodystrophy, at midpoints of intervals and the bars are the proportion standard error. The binomial model fitted indicated a good fit.

\begin{tabular}{|l|l|l|l|}
\hline Coefficients & Estimate & Estimated Standard Error & P value \\
\hline Intercept & -2.243956 & 0.260215 & $p<2 \mathrm{e}-16$ \\
\hline Time on Treatment & 0.050945 & 0.009764 & $p=1.81 \mathrm{e}-07$ \\
\hline
\end{tabular}

Table 4: The logistic regression (binomial) model for lipodystrophy incidence against time on stavudine.

where time on treatment was shown to be strongly correlated with development of this ADR. The results in Figure 3 and Table 4 show that the duration on treatment with stavudine correlated with an increase in incidences of lipodystrophy. For those on stavudine, females were found to be more susceptible to lipodystrophy $(\mathrm{OR}=3.35(1.55,7.22)$ : $\mathrm{p}=0.0023$ ) in comparison to males with $36 \%$ of females exhibiting this side effect versus $12 \%$ of males. Furthermore, females had significant odds of susceptibility to lipodystrophy compared to males for all patients on ART with odds of 4.14 (CI $(2.15,8.01)$ ( $\mathrm{p}<0.0001)$ ). HIV infected patients with lipodystrophy had a significantly higher mean BMI in comparison to those without $\left(23 \mathrm{~kg} / \mathrm{m}^{2}\right.$ vs. $\left.21 \mathrm{~kg} / \mathrm{m}^{2} ; \mathrm{p}<0.0029\right)$. Duration on ART had an impact on predisposition to lipodystrophy (controls vs. cases) (15 months vs. 33 months, $\mathrm{p}<0.0001$ ).

\section{Central nervous system ADRs}

The patients on an efavirenz containing regimen (ART only)

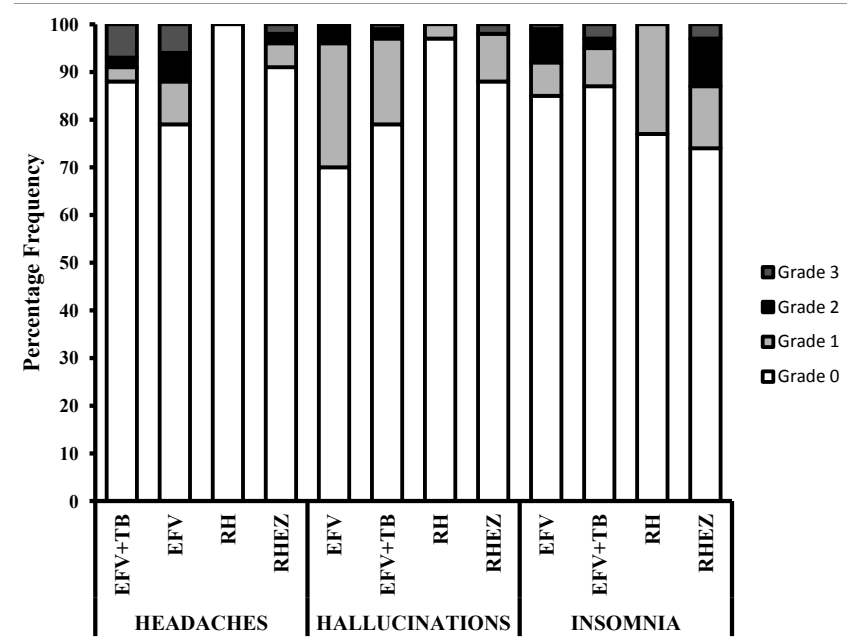

Figure 4: The frequencies of patients experiencing CNS related side effects, on efavirenz containing regimens and on TB treatment.

were found to have a higher mean BMI as compared to those on both ART (containing efavirenz) and TB treatment $\left(22.5 \mathrm{~kg} / \mathrm{m}^{2}\right.$ vs. $21.5 \mathrm{~kg} /$ $\left.m^{2}, \mathrm{p}=0.0758\right)$. A statistically significant difference was observed, for duration on ART (containing efavirenz) as compared to ART and TB treatment and those on TB treatment only (median (IQR) months) $(14(7,24) ; 6(4,13) ; 3.5(2,6.5): \mathrm{p}=0.0001)$ respectively.

Figure 4 represents a detailed analysis of central nervous system (CNS) side effects. There was a significant difference in frequencies of CNS side effects for those who were on an efavirenz containing regimen compared to those on a non-efavirenz containing regimen (ART only) ( $43 \%$ vs. $17 \%, \mathrm{p}<0.0001$ ). However, there was no significant difference in the frequencies of CNS side effects between those who were on anti-TB drugs compared to those who were on both ART (containing efavirenz) and anti TB drugs ( $29 \%$ vs. $38 \%, p=0.19)$ respectively. The same was noted in the frequency differences between those on ART (efavirenz containing regimen) and ART and TB treatment (43\% vs. $38 \%, \mathrm{p}=0.20$ ). The most prevalent CNS side effect for patients on efavirenz was hallucinations with a frequency of $25 \%$ (Figure 4 ). The patients on TB treatment had sleep problems especially those on the treatment combination of isoniazid, rifampcin, ethambutol and pyrazinamide.

The duration of treatment for patients on RHEZ was found to have been significantly less compared to those who were on $\mathrm{RH}$ only (3.6 months vs. 4.8 months; $\mathrm{p}=0.034)$. Exclusively, TB treatment patients with CNS side effects had significantly higher BMI $\left(23.23 \mathrm{~kg} / \mathrm{m}^{2}\right.$ vs. 21.4 $\mathrm{kg} / \mathrm{m}^{2} ; \mathrm{p}=0.046$ ) compared to those without CNS side effects.

\section{Peripheral neuropathy}

In patients and controls for peripheral neuropathy, the duration on ART alone (containing stavudine) as compared to ART (containing stavudine) and TB treatment and those on TB treatment only, showed statistically significant differences, (median (IQR) months) $(15(9,24)$; $6(4,12) ; 3.5(2,6.5): \mathrm{p}=0.0001)$ respectively. Individuals on combined $\mathrm{TB}$ treatment and a stavudine containing regimen had a lower mean BMI compared to those on ART (stavudine containing regimen only) $\left(21.5 \mathrm{~kg} / \mathrm{m}^{2}\right.$ vs. $\left.22.6 \mathrm{~kg} / \mathrm{m}^{2}, \mathrm{p}=0.0391\right)$. Age showed statistically significant differences for susceptibility to peripheral neuropathy. When the treatment groups were considered independently, a greater susceptibility to peripheral neuropathy was found for those over 40 

Reactions (Lipodystrophy, CNS, Peripheral Neuropathy, and Hypersensitivity Reactions) Associated with Anti-Retroviral Therapy (ART) and Anti-Tuberculosis Treatment in Outpatients in Zimbabwe. J AIDS Clin Res 4: 203. doi:10.4172/2155-6113.1000203

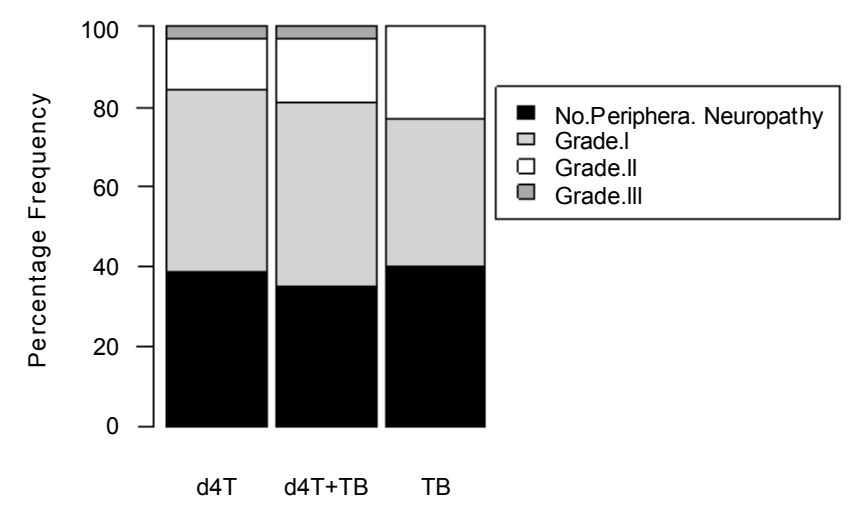

Figure 5: Percentage frequency of patients suffering from peripheral neuropathy on stavudine containing regimen and/or anti-TB drugs.

years for ART only (containing stavudine) $(\mathrm{OR}=2.4$, CI $(1.21,4.74)$ : $\mathrm{p}=0.018)$, for ART (containing stavudine) and TB treatment $(\mathrm{OR}=2.63$, $\mathrm{CI}(0.91,8.23): \mathrm{p}=0.067)$, and for those on TB treatment only $(\mathrm{OR}=1.87$, CI $(0.77,4.57): \mathrm{p}=0.243)$. Considering all patients on a stavudine containing regimen, age $>40 \mathrm{yrs}$ was associated with increased risk of peripheral neuropathy $(\mathrm{OR}=1.91$, CI $(1.09,3.34)$ : $\mathrm{p}=0.032)$. Figure 5 shows a comparison of $\mathrm{PN}$ in the different treatment groups with similar frequencies of grade I and II level PN observed and level III PN observed only in those patients whose treatment included stavudine.

\section{Skin hypersensitivity}

Skin hypersensitiity reactions were observed in $14 \%$ of patients currently on nevirapine containing HAART. The frequency of $48 \%$ reported by patients who had previously been on nevirapine containing HAART is accounted for by patients who were changed from a nevirapine containing ART regimen to one based on efavirenz due to the skin hypersensitivity reaction caused by nevirapine. Females were more susceptible to skin hypersensitivity reactions $(\mathrm{OR}=4.65, \mathrm{CI}$ $(1.07,27.84): p=0.0329)$ compared to males, for patients on anti-TB drugs. This gender susceptibility to skin hypersensitity reactions was not observed in females on HAART.

\section{Discussion}

This study has simultaneously evaluated major ADRs associated with the use of ARVs and anti-TB drugs. This approach has allowed us to explore the contributions of various drug combinations on the occurrence and severity of ADRs, thus offering a clinically relevant qualitative and quantitative measure of the burden of ADRs in the treatment of HIV/AIDS, TB and HIV-TB co-infection.

ADRs have been reported to be the $4^{\text {th }}$ leading cause of death in the USA [18] and accounting for 197000 deaths in Europe annually [19]. The cost of ADRs to the healthcare system is enormous with the USA estimating it at US\$137-177 billion a year [20] and Europe at 79 billion Euros a year [19]. It has been reported that $45 \%$ of patients who are started on ART, discontinue or change treatment during the first year, frequently due to poor treatment tolerance and adverse drug reactions [21]. The high incidence of ADRs in patients on ART and anti-TB treatment that we have observed in this study in Zimbabwe is in agreement with reports from others [22] and highlights safety issues in the treatment of HIV/AIDS and/or TB. Our study has shown that peripheral neuropathy is the most common ADR in patients on ART and TB treatment in agreement with the work of others [23]. In
Kenya, an analysis of 1490 suspected ADR reports revealed that $79 \%$ of ADRs were related to antiretroviral medicines [24]. The most common ARV-related ADRs observed in that study were lipoatrophy, nausea and vomiting, peripheral neuropathy, pruritus rash, anaemia, erythema multiforme, and maculopapular rash. A survey in the use of ARVs and management of HIV/AIDS in Nigeria reported that $26 \%$ of the patients had experienced ADRs to ARVs [25]. This has been supported by recent studies by Eluwa et al, [26] who also showed that ADRs were more likely to be experienced in the first 6 months of treatment. In a South African study involving 665 adults admitted to a hospital in an HIV/ AIDS endemic region, $6.3 \%$ patients were admitted as a result of an ADR and another 6.3\% developed an ADR in hospital [27]. Given this high incidence of ADRs to ART and anti-TB drugs, future studies need to evaluate the cost to the healthcare system with respect to hospital admissions, poor compliance leading to possible drug resistance, and lost working hours due to absenteeism due to ADRs.

Previous studies have shown strong associations of stavudine with lipodystrophy and peripheral neuropathy [22,28-30], efavirenz with CNS [31], isoniazid with peripheral neuropathy [23], and nevirapine with skin hypersensitivity reactions [32,33]. In this study we have seen similar trends but also noted additional drug combination specific ADRs patterns. Consideration of the role of gender and duration of treatment could help clinicians rationalise ADRs they observe in patients.

Similarly to other findings with regards to high incidences of peripheral neuropathy, our results further showed that older age ( $>40 \mathrm{yrs}$ ) is a risk factor for peripheral neuropathy, particularly for those on stavudine containing regimens and this agrees with a number of studies $[30,34,35]$. To quote one comment from a patient experiencing peripheral neuropathy "The discomfort I get with this medication is so severe at times that I don't sleep through the night, I regret taking the medication." From some of the comments given by patients, it is clear that adherence to a treatment regimen might be compromised because of adverse drug reactions.

Our findings on stavudine associated lipodystrophy agree with a number of studies reporting increased susceptibility for women as compared to men [36,37]. Cabrero et al. [38] notes that significantly more women reported lipoatrophy of lower limbs and buttocks as well as lipohypertrophy as compared to men. However they noted no gender differences in the global prevalence of lipodystrophy for patients on HAART. A higher body mass index was associated with development of lipodystrophy during treatment for those on HAART. We also observed that prolonged use of a stavudine containing regimen increases the risk for lipodystrophy in agreement other reports [28,39].

Our results show a significant number of patients have CNS side effects on efavirenz containing ART regimens, efavirenz containing ART regimens $+\mathrm{TB}$ treatment and $\mathrm{TB}$ treatment only regimens compared to patients on non EFV ( $43 \%$ vs. $17 \%, \mathrm{p}<0.00001)$. Several studies have proposed the need to reduce the dose of efavirenz [14,40,41] in some patients in order to reduce these adverse drug reactions and successful therapeutic outcomes have been demonstrated for slow metabolisers or those with low clearance of efavirenz [40].

Nevirapine is the most commonly used NNRTI in developing countries because of its lower cost, compared with efavirenz. Nevirapine-induced hypersensitivity rash has been reported to occur in $16 \%-20 \%$ of patients in studies in developed countries $[32,42,43]$. Our results show $14 \%$ of the patients on a nevirapine regimen have this side effect and $48 \%$ of the patients on a non-nevirapine regimen, 
Citation: Nemaura T, Dhoro M, Nhachi C, Kadzirange G, Chonzi P (2013) Evaluation of the Prevalence, Progression and Severity of Common Adverse Reactions (Lipodystrophy, CNS, Peripheral Neuropathy, and Hypersensitivity Reactions) Associated with Anti-Retroviral Therapy (ART) and Anti-Tuberculosis Treatment in Outpatients in Zimbabwe. J AIDS Clin Res 4: 203. doi:10.4172/2155-6113.1000203

after having been changed from nevirapine due to skin hypersensitivity. We also observed that females are more susceptible than males to skin hypersensitivity arising from TB medication.

\section{Conclusions}

ART is supposed to increase life expectancy and improve the quality of life of HIV/AIDS and TB patients but given the extent of ADRs observed in this study, it appears that the quality of life of most patients is compromised. This has a number of long term implications which include reduced economic productivity of a significant number of people and a new type of stigmatisation associated with the visual appearances clearly associated with ART ADRs.

Our study shows the enormous ADRS burden due to ART and antiTB treatment which needs further studies to estimate its cost to the healthcare system. The studies also highlight the need to understand what predisposes some people to the ADRs with the objective of finding biomarkers that can be used to guide ART towards safe and efficacious outcomes. There are now an increasing number of reports which indicate that there might be some genetic markers predictive of the occurrence and severity of some of these ADRs.

Using samples collected from these patients, we will conduct pharmacogenomic studies in search of such biomarkers that could assist clinicians in tailor making ART regimens for efficacy and safety.

\section{Acknowledgements}

The authors gratefully acknowledge Prof. Julia Hasler's thorough review of the manuscript. This work was funded from ISP and EDCTP research grants.

\section{References}

1. Dude AM (2011) Spousal intimate partner violence is associated with HIV and Other STIs among married Rwandan women. AIDS Behav 15: 142-152.

2. WHO (2009) Global Tuberculosis Control: Epidemiology, Strategy, Financing.

3. Gandhi NR, Moll AP, Lalloo U, Pawinski R, Zeller K, et al. (2009) Successful integration of tuberculosis and HIV treatment in rural South Africa: the Sizonq'oba study. J Acquir Immune Defic Syndr 50: 37-43.

4. WHO (2004) Global Burden Diseases.

5. CDC (2013) CDC Updated Slide Set: HIV Incidence in the United States 20062009.

6. WHO (2005) Summary country profile for HIVIAIDS treatment Scale-up.

7. WHO Report (2009) Epidemiological Fact Sheet on HIV and AIDS. Core data and epidemiology and response Zimbabwe.

8. Cohen MS, Chen YQ, McCauley M, Gamble T, Hosseinipour MC, et al. (2011) Prevention of HIV-1 infection with early antiretroviral therapy. N Engl J Med 365: 493-505.

9. Kozal MJ, Kroodsma K, Winters MA, Shafer RW, Efron B, et al. (1994) Didanosine resistance in HIV-infected patients switched from zidovudine to didanosine monotherapy. Ann Intern Med 121: 263-268.

10. Hammer SM, Squires KE, Hughes MD, Grimes JM, Demeter LM, et al. (1997) A controlled trial of two nucleoside analogues plus indinavir in persons with human immunodeficiency virus infection and CD4 cell counts of 200 per cubic millimeter or less. AIDS Clinical Trials Group 320 Study Team. N Engl J Med 337: 725-733.

11. Staszewski S, Morales-Ramirez J, Tashima KT, Rachlis A, Skiest D, et al. (1999) Efavirenz plus zidovudine and lamivudine, efavirenz plus indinavir, and indinavir plus zidovudine and lamivudine in the treatment of HIV-1 infection in adults. Study 006 Team. N Engl J Med 341: 1865-1873.

12. Montessori V, Press N, Harris M, Akagi L, Montaner JS (2004) Adverse effects of antiretroviral therapy for HIV infection. CMAJ 170: 229-238.

13. WHO (2009) A guide for adaptation and implementation: Antiretroviral therapy for HIV Infection in adults and adolescence.
14. Nyakutira C, Röshammar D, Chigutsa E, Chonzi P, Ashton M, et al. (2008) High prevalence of the CYP2B6 516G-->T( ${ }^{*} 6$ ) variant and effect on the population pharmacokinetics of efavirenz in HIVIAIDS outpatients in Zimbabwe. Eur J Clin Pharmacol 64: 357-365.

15. Dart Trial Team (2008) Twenty-four-week safety and tolerability of nevirapine vs. abacavir in combination with zidovudine/lamivudine as first-line antiretroviral therapy: a randomized double-blind trial (NORA). Trop Med Int Health 13: 6-16.

16. RSC (2009) DAIDS table for grading the severity of adult and paediatric adverse events. DAIDS Regulatory support centre.

17. ICSSC (2003) Monitoring and Reporting Adverse Events. International Clinical Studies Support Center.

18. Lazarou J, Pomeranz BH, Corey PN (1998) Incidence of adverse drug reactions in hospitalized patients: a meta-analysis of prospective studies. JAMA 279 1200-1205.

19. Archibald K, Coleman R, Foster C (2011) Open letter to UK Prime Minister David Cameron and Health Secretary Andrew Lansley on safety of medicines. Lancet 377: 1915.

20. Ernst FR, Grizzle AJ (2001) Drug-related morbidity and mortality: updating the cost-of-illness model. J Am Pharm Assoc (Wash) 41: 192-199.

21. Lubomirov R, Colombo S, di lulio J, Ledergerber B, Martinez R, et al. (2011) Association of pharmacogenetic markers with premature discontinuation of first-line anti-HIV therapy: an observational cohort study. J Infect Dis 203: 246257.

22. Hulgan T, Haas DW, Haines JL, Ritchie MD, Robbins GK, et al. (2005) Mitochondrial haplogroups and peripheral neuropathy during antiretrovira therapy: an adult AIDS clinical trials group study. AIDS 19: 1341-1349.

23. Breen RA, Lipman MC, Johnson MA (2000) Increased incidence of periphera neuropathy with co-administration of stavudine and isoniazid in HIV-infected individuals. AIDS 14: 615.

24. Pandit J, Abwao E, Muthuri G, Njeri M, Khaemba C, et al. (2011) The Kenya National Medicines Information and Pharmacovigilance Centre Newsletter.

25. Federal Ministry of Health and WHO (2003) Situation of Antiretroviral drug use in Nigeria.

26. Eluwa GI, Badru T, Agu KA, Akpoigbe KJ, Chabikuli O, et al. (2012) Adverse drug reactions to antiretroviral therapy (ARVs): incidence, type and risk factors in Nigeria. BMC Clin Pharmacol 12: 7.

27. Mehta U, Durrheim DN, Blockman M, Kredo T, Gounden R, et al. (2008) Adverse drug reactions in adult medical inpatients in a South African hospital serving a community with a high HIVIAIDS prevalence: prospective observational study. Br J Clin Pharmaco 65: 396-406.

28. Wangsomboonsiri W, Mahasirimongkol S, Chantarangsu S, Kiertiburanaku S, Charoenyingwattana A, et al. (2010) Association between HLA-B*4001 and Lipodystrophy among HIV-Infected Patients from Thailand Who Received a Stavudine-Containing Antiretroviral Regimen. Clin Infect Dis 50: 597-604.

29. van Oosterhout JJ, Bodasing N, Kumwenda JJ, Nyirenda C, Mallewa J, et al (2005) Evaluation of antiretroviral therapy results in a resource-poor setting in Blantyre, Malawi. Trop Med Int Health 10: 464-470.

30. Phan V, Thai S, Choun K, Lynen L, van Griensven J (2012) Incidence of treatment-limiting toxicity with stavudine-based antiretroviral therapy in Cambodia: a retrospective cohort study. PLoS One 7: e30647.

31. Gatanaga H, Hayashida T, Tsuchiya K, Yoshino M, Kuwahara T, et al. (2007) Successful efavirenz dose reduction in HIV type 1-infected individuals with cytochrome P450 2B6 *6 and *26. Clin Infect Dis 45: 1230-1237.

32. Warren KJ, Boxwell DE, Kim NY, Drolet BA (1998) Nevirapine-associated Stevens-Johnson syndrome. Lancet 351: 567.

33. Bersoff-Matcha SJ, Miller WC, Aberg JA, van Der Horst C, Hamrick Jr HJ, et al (2001) Sex differences in nevirapine rash. Clin Infect Dis 32: 124-129.

34. Evans SR, Ellis RJ, Chen H, Yeh TM, Lee AJ, et al. (2011) Peripheral neuropathy in HIV: prevalence and risk factors. AIDS 25: 919-928.

35. Cherry CL, Affandi JS, Imran D, Yunihastuti E, Smyth K, et al. (2009) Age and height predict neuropathy risk in patients with HIV prescribed stavudine. Neurology 73: 315-320.

36. Galli M, Veglia F, Angarano G, Santambrogio S, Meneghini E, et al. (2003) 
Citation: Nemaura T, Dhoro M, Nhachi C, Kadzirange G, Chonzi P (2013) Evaluation of the Prevalence, Progression and Severity of Common Adverse Reactions (Lipodystrophy, CNS, Peripheral Neuropathy, and Hypersensitivity Reactions) Associated with Anti-Retroviral Therapy (ART) and Anti-Tuberculosis Treatment in Outpatients in Zimbabwe. J AIDS Clin Res 4: 203. doi:10.4172/2155-6113.1000203

Page 7 of 7

Gender differences in antiretroviral drug-related adipose tissue alterations. Women are at higher risk than men and develop particular lipodystrophy patterns. J Acquir Immune Defic Syndr 34: 58-61.

37. Castelnuovo B, Kiragga A, Kamya MR, Manabe Y (2011) Stavudine toxicity in women is the main reason for treatment change in a 3-year prospective cohort of adult patients started on first-line antiretroviral treatment in Uganda. J Acquir Immune Defic Syndr 56: 59-63.

38. Cabrero E, Griffa L, Burgos A, HIV Body Physical Changes Study Group (2010) Prevalence and impact of body physical changes in HIV patients treated with highly active antiretroviral therapy: results from a study on patient and physician perceptions. AIDS Patient Care STDS 24: 5-13.

39. Martin A, Smith D, Carr A, Hoy J, Chuah J, et al. (2004) Progression of lipodystrophy (LD) with continued thymidine analogue usage: long-term follow-up from a randomized clinical trial (the PIILR study). HIV Clin Trials 5: 192-200.

40. Gatanaga H, Oka S (2009) Successful genotype-tailored treatment with smalldose efavirenz. AIDS 23: 433-434.

41. van Luin M, Gras L, Richter C, van der Ende ME, Prins JM, et al. (2009) Efavirenz dose reduction is safe in patients with high plasma concentrations and may prevent efavirenz discontinuations. J Acquir Immune Defic Syndr 52 240-245.

42. Carr A, Cooper DA (2000) Adverse effects of antiretroviral therapy. Lancet 356 1423-1430.

43. Pollard RB, Robinson P, Dransfield K (1998) Safety profile of nevirapine a nonnucleoside reverse transcriptase inhibitor for the treatment of human immunodeficiency virus infection. Clin Ther 20: 1071-1092. 